\title{
Laser-induced damage and contamination testing for the next generation of LIDAR space optics
}

Nils Bartels, Paul Allenspacher, Thimotheus Alig, Istvan Balasa, Helmut Schröder, et al.

Nils Bartels, Paul Allenspacher, Thimotheus Alig, Istvan Balasa, Helmut Schröder, Gabriele Taube, Wolfgang Riede, "Laser-induced damage and contamination testing for the next generation of LIDAR space optics," Proc. SPIE 11852, International Conference on Space Optics - ICSO 2020, 1185260 (11 June 2021); doi: 10.1117/12.2600036

SPIE Event: International Conference on Space Optics - ICSO 2021, 2021, Online Only 


\section{International Conference on Space Optics-ICSO 2020}

Virtual Conference

30 March-2 April 2021

Edited by Bruno Cugny, Zoran Sodnik, and Nikos Karafolas
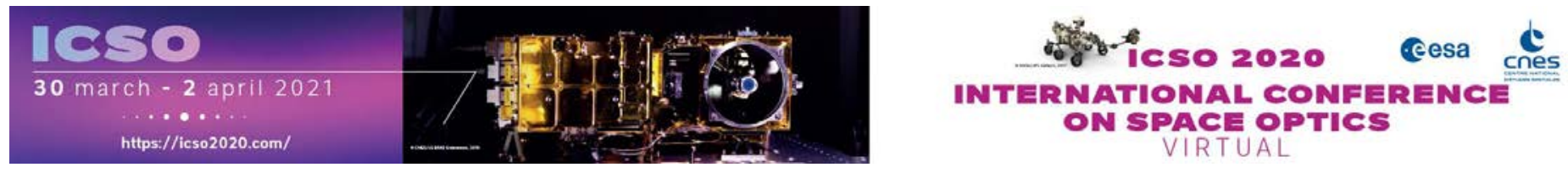

\section{Laser-induced damage and contamination testing for the next generation of LIDAR space optics}

\section{Cesa issopereatings denes}




\title{
Laser-induced damage and contamination testing for the next generation of LIDAR space optics
}

\author{
Nils Bartels*a, Paul Allenspacher ${ }^{\mathrm{a}}$, Thimotheus Alig ${ }^{\mathrm{b}}$, Istvan Balasa ${ }^{\mathrm{b}}$, Helmut Schröder ${ }^{\mathrm{a}}$, Gabriele \\ Taube $^{\mathrm{a}}$ and Wolfgang Riede ${ }^{\mathrm{a}}$ \\ anstitute of Technical Physics, German Aerospace Center (DLR), Pfaffenwaldring 38-40, 70569 \\ Stuttgart, Germany; ${ }^{b}$ Laser Zentrum Hannover e.V., Hollerithallee 8, 30419 Hannover, Germany
}

\begin{abstract}
We have recently reported a method to improve the laser-induced damage threshold of UV laser optics by mitigating damage precursors (nano-sized absorbers) during the manufacturing of ion-beam sputtered, anti-reflective optical coatings. To further optimize parameters of the coating and particle mitigation schemes, we had to assess the damage resistance of laser optics with a low density of damage precursors. This was achieved using large area raster scans in which a highintensity laser beam was scanned over the optical surface. Via image processing of microscopic data, we then derived the density and size distribution of laser-induced damages for each raster scan. This advanced test method is described in this work and prepared the path to the manufacturing of improved laser optics that can be used to increase the performance and reliability of lasers in future space missions. Furthermore, we report on the comparison of standard and improved laser optics in tests of laser-induced contamination at 355 and $266 \mathrm{~nm}$.
\end{abstract}

Keywords: Laser-induced damage testing, Raster scan, Light detection and ranging (LIDAR), Ion beam sputtering, Coating optimization

*nils.bartels@dlr.de; phone +49 711 68628244; dlr.de

\section{INTRODUCTION}

Several past and future scientific space missions use LIDAR systems with nanosecond-pulsed, high-power lasers to carry out global measurements, e.g. of wind speeds (ESA Aeolus), atmospheric aerosol distributions (ESA EarthCARE) or the ice sheet mass balance (NASA ICESat/ICESat 2). For these laser systems, laser-induced damage of optical components is a major risk for the entire space mission as laser optics damaged in orbit cannot be replaced. Research to increase the damage resistance especially in the ultraviolet spectral range not only contributes to mitigate this risk, but also allows for the design of better laser systems with higher performance and lower mass. [1]

For nanosecond-pulsed lasers, laser-induced damage is well-known to originate from nanometer-sized particles introduced to the optics during substrate preparation (e.g. polishing) or the coating deposition. [2, 3, 4, 5] In a project called "Particle mitigation in high power laser optics" (ESA contract AO 1-8683/16/NL/BJ) we worked on improving the laser-induced damage resistance of ion-beam sputtered optics (anti-reflective at $355 \mathrm{~nm}$ ) by eliminating damage precursors using ion etching (strategy 1) or laser etching (strategy 2) of the fused silica substrate and additionally during the coating after the deposition of each dielectric layer.

In order to be able to optimize parameters of the particle mitigation schemes it was necessary to perform damage tests that provide statistically significant data on the damage resistance of the laser optics. A typical S-on-1 test according to the ISO 21254 standard [6] only covers an effective area of $1 \mathrm{~mm}^{2}$. In particular for high quality optical components (e.g. IBScoated super polished substrates) this may be insufficient for detecting low density damage precursors. To overcome this limitation, we instead use large area raster scans [7, 8] with an area of $60 \mathrm{~mm}^{2}$. In these tests, the laser focused to a specific energy density is scanned over the optical surface. The irradiated area is then analyzed with differential interference contrast (DIC) and dark field (DF) microscopy.

In order to assist the analysis of DIC and DF micrographs, we have developed a script written in the Python programming language that counts the laser-induced damages and classifies them according to their size. By comparing micrographs taken before and after laser irradiation, additional information (e.g. whether a damage occurred near a previously detected 
surface defect) can be obtained. The calculated damage density is then used to compare laser optics manufactured with different coating or cleaning parameters and to assist in the parameter choice for the next manufacturing run in a looped optimization process.

\section{S-on-1 test procedure:}
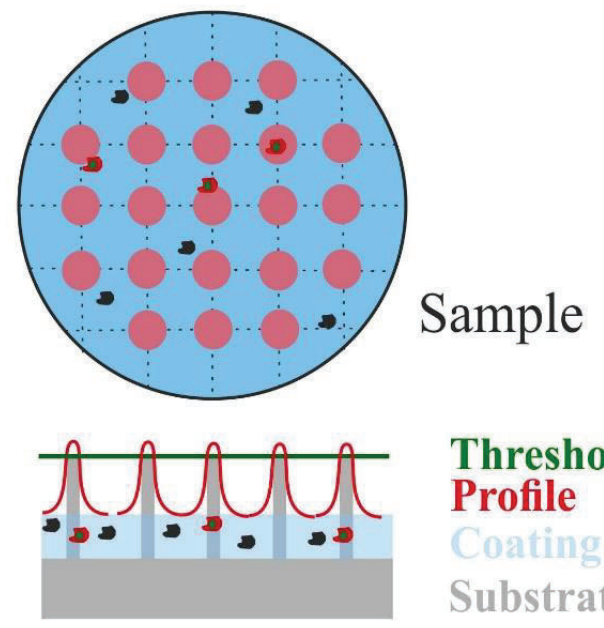

Threshold

Profile

Substrate

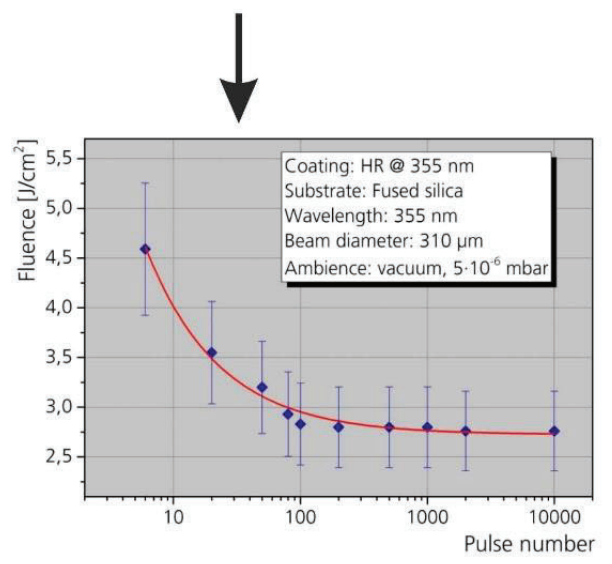

Interrogation of specific test sites

Result: Damage threshold (LIDT)

\section{Large-area raster scan:}
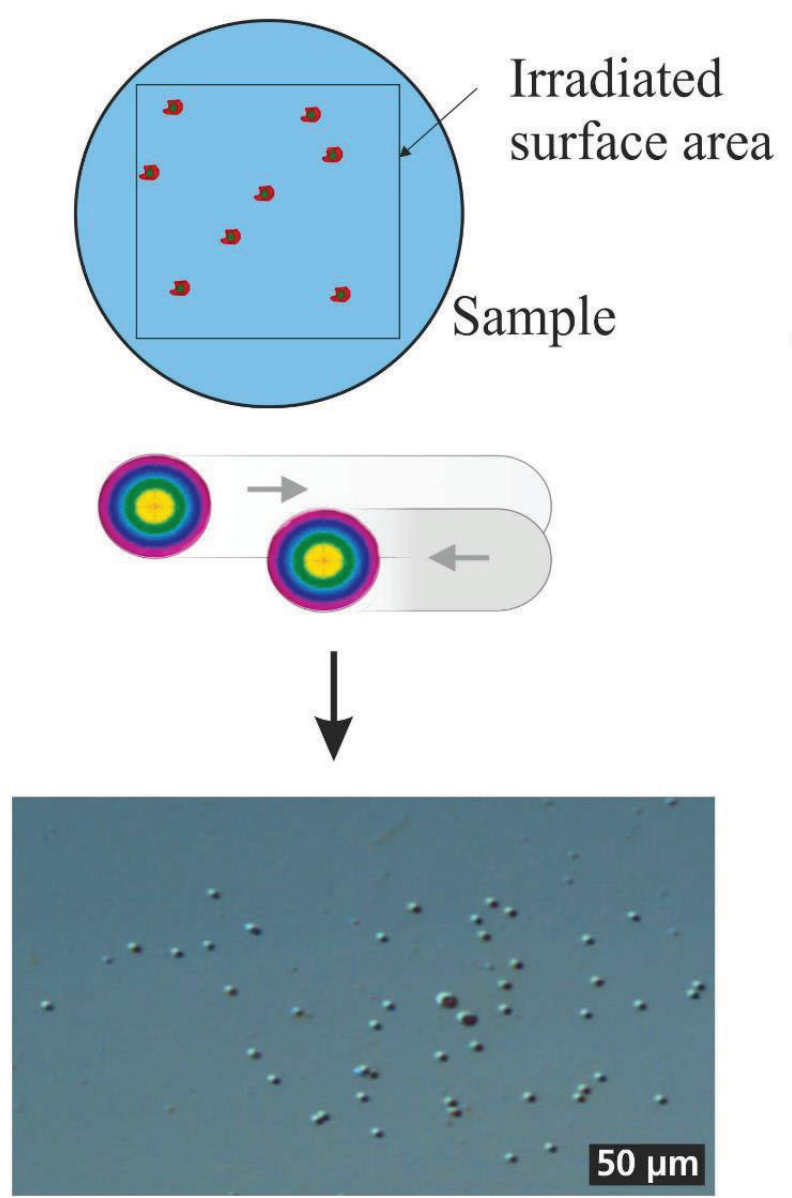

Interrogation of a large area at specific laser fluence Result: Damage density (and size distribution)

Figure 1: Comparison of test procedures for laser-induced damage testing.

While we have previously reported details on the particle mitigation strategy [9], this work focuses in more detail on the test method and the information that can be obtained from a computerized data evaluation in large area raster scans. Furthermore, we compare improved laser optics (meaning optics manufactured using particle mitigation schemes) to optics manufactured via conventional IBS sputtering in tests of laser-induced contamination.

\section{EXPERIMENTAL}

\subsection{Manufacturing of optical coatings and particle mitigation schemes}

Details on the manufacturing of laser-optics have been reported previously [9]. Standard optics (Sample Ref. \#015 and \#042) were manufactured by coating super-polished fused silica substrates via conventional ion beam sputtering (IBS) to 
produce anti-reflective (AR) optical coatings at $355 \mathrm{~nm}$. The coating was realized with four layers of aluminum oxide and silicon dioxide.

Furthermore, two different approaches to reduce the number of damage precursors in the optical coating were tested: ion etching with a secondary ion source (strategy 1) and laser etching with a laser source (strategy 2). Both approaches for particle mitigation were first tested purely as a substrate pretreatment (samples \#007 to \#013 for ion etching and samples \#018 to \#034 for laser etching, respectively) and then also applied during coating in the IBS coating machine.

\subsection{Test strategy}

We decided to test the manufactured optical coatings with large area raster scans on an area of $60 \mathrm{~mm}^{2}$ using two different laser fluences: $15 \mathrm{~J} / \mathrm{cm}^{2}$ and $25 \mathrm{~J} / \mathrm{cm}^{2}$. The setup used for laser-induced damage testing at DLR was described previously. [10] Briefly, the third harmonic $(355 \mathrm{~nm})$ of a pulsed Nd:YAG laser (Innolas DPSS 500, pulse repetition rate of $100 \mathrm{~Hz}$, $8.2 \mathrm{~ns}$ pulse duration at $355 \mathrm{~nm}(\mathrm{FWHM})$ ) was focused to the optics under test giving a near-Gaussian beam profile with a typical beam diameter (1/ $\mathrm{e}^{2}$-diameter of a Gaussian fit) of $300 \mu \mathrm{m}$. The laser light was irradiated line-by-line with a number of 10 pulses per effective Gaussian beam area by adjusting the forward feed of the sample holder mounted to a bidirectional translation stage. The high scanning speed (meaning a low number of laser pulses per area) in combination with an online damage detection system minimizes damage growth due to the subsequent irradiation of laser-induced damages. Before and after each raster scan, the optical surface was investigated via differential interference ("Nomarksi") and dark field microscopy using an Olympus BX61 microscope at 200x magnification. Due to the large surface area and the high magnification the stitched micrographs had a fairly large size of $\sim 4 \mathrm{GPx}$ ("giga pixels"), which corresponds to the size of approximately 167 image files from modern digital cameras (assuming an image size of 24 mega pixels). The large size of the images requires an efficient and automatic data evaluation. The test strategy is visualized in Figure 2.

\section{Manufacturing (with parameter variation of particle mitigation schemes)}

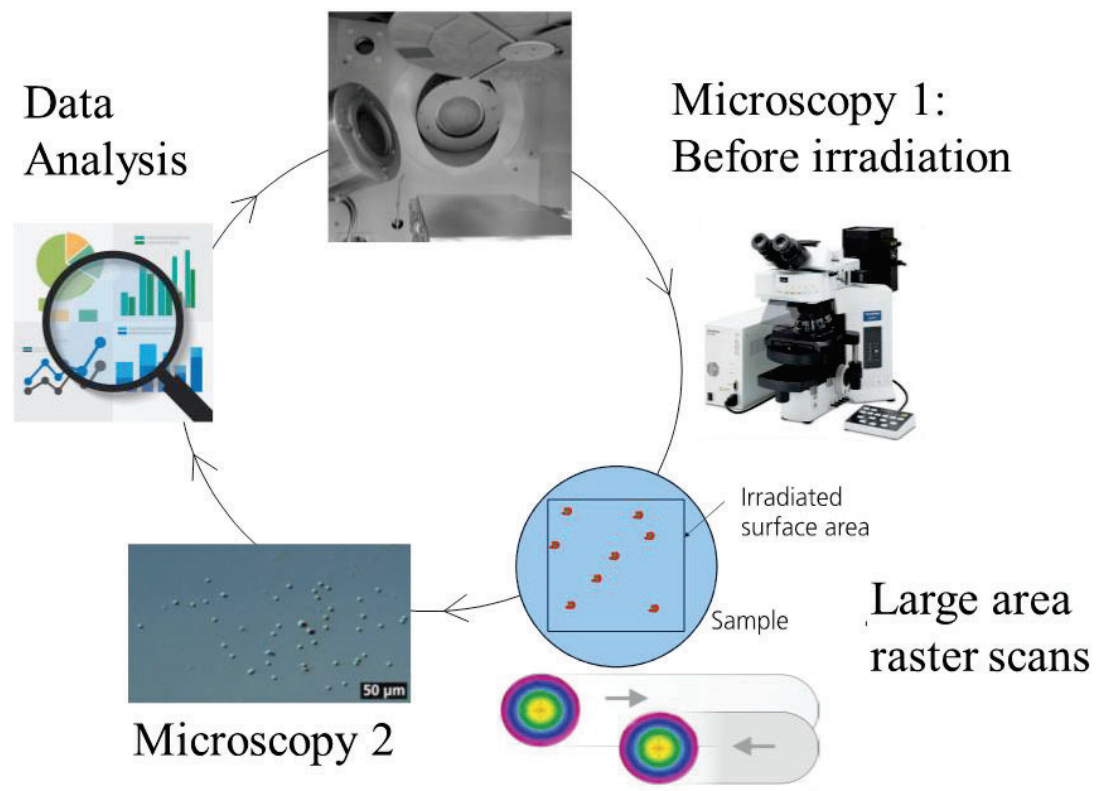

Figure 2: Test strategy for the coating optimization. 


\subsection{Data evaluation}

In order to compare the number of damages created in the raster scans of the different manufactured laser optics, we developed a script written in the programming language Python that counts the number of damages and evaluates their size distribution.

For the evaluation we decided to use dark field microscopic images, since such micrographs taken with well-defined settings (e.g. illumination time of $1 \mathrm{~s}$ ) were found to have more reproducible brightness distributions than Nomarski micrographs. For the comparison of identical positions in the micrographs, dark field images taken before and after irradiation were aligned. This was achieved via a coordinate transformation that rotates and translates the images to match the pixel coordinates of markers written to just below the surface of each optical substrate via laser beam writing. The micrographs were saved in a single stitched image file of 4GPx and binned to a size of $\sim 1 \mathrm{GPx}(2 \times 2$-pixel binning).

In order to detect laser-induced damages, an algorithm is used to look for connected pixels (connected horizontally, vertically and diagonally; meaning that each pixel has 8 neighbors) with an intensity above a specific brightness threshold. This evaluation is performed for dark field micrographs taken before irradiation (counting the number of "defects") and after laser irradiation (counting the combined number of "defects and damages").

In principle, one could assume that the number of "damages" can then be calculated by subtracting the number of "defects" (micrograph prior to irradiation) from the number of "defects and damages" (micrograph after irradiation). The issue with this approach is that - in particular for raster scans with a low laser fluence - it can easily be obscured from effects such as laser-induced cleaning (e.g. cleaning residuals from the cleaning bath [10]) or a large number of laser-induced damages induced by a single small dust particle, which can be encountered even in a clean room environment. Figure 3 shows examples of such low probability but sometimes nonetheless important effects.
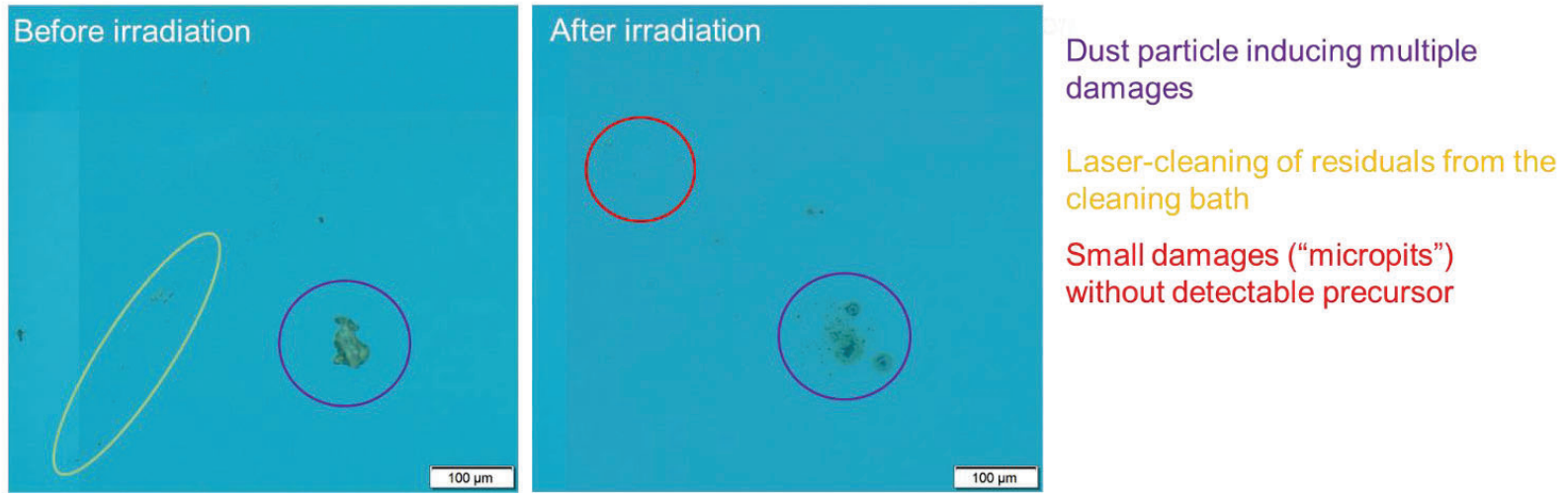

Figure 3: Challenges to classify laser-induced damages.

In order to find an easily accessible metric to assess the damage resistance of the optical coating neglecting such effects, we decided to additionally look for "damages without detected precursor". Here, "damages without visible precursor" mean damages that were generated in an area on the optical surface without any defect in its vicinity prior to the raster scan (the minimum distance was defined to $\sim 50 \mu \mathrm{m}$ ). In practice, this was achieved by a masking algorithm. This algorithm detects defects in the dark field images taken before irradiation (left panel of Figure 4). The area around any detected defect is then not taken into consideration when counting the number of damages in the dark field micrograph taken after laser irradiation (right panel of Figure 4). 


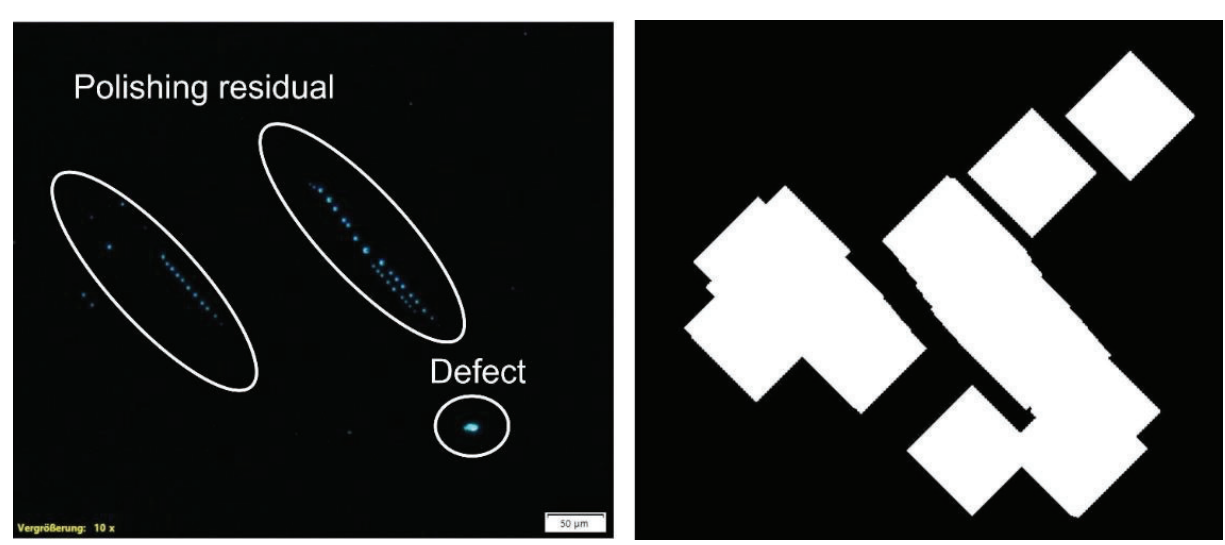

Figure 4: Masking of a polishing residual and a defect in the data evaluation.

The final results of the Python script are then a list with the number and size of objects detected prior to laser irradiation ("the number of defects"), a list with the number and size of objects detected after irradiation ("the number of defects and damages") and the number and size of "damages without visible precursor" obtained using the masking algorithm. In addition to that, an image file comparing microscopic images at a specific position (taken before and after irradiation) is generated for each object. Examples of these automatically generated images are provided in Figure 5.

\section{Standard Optics \#015, Damage 4}
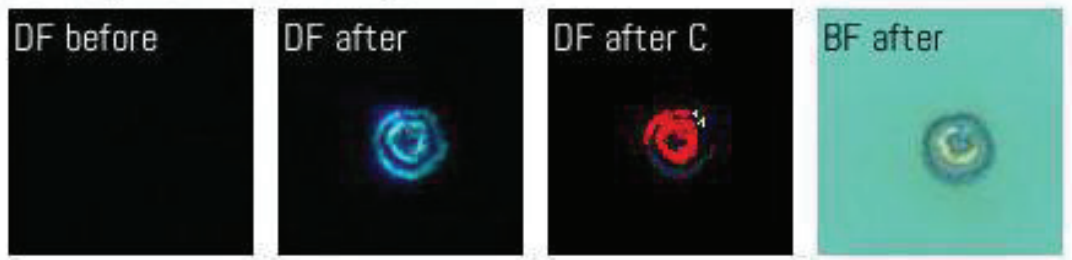

Size (@25 J/cm2): 270Pixels, $(x, y)=(11538,1532)$

\section{Standard Optics \#015, Damage 7}
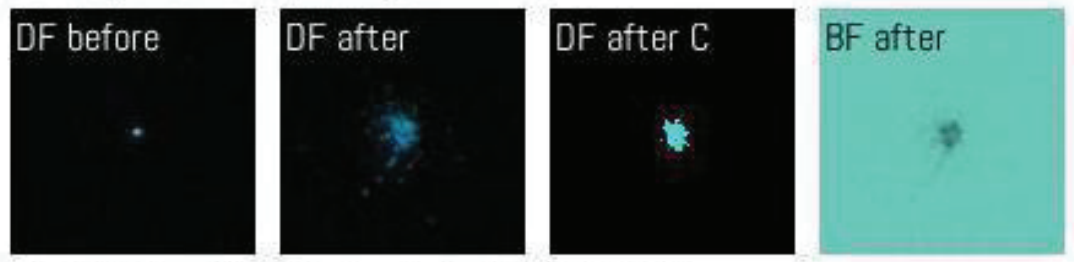

Size (@15 J/cm2): 80Pixels, $(x, y)=(15425,5743)$

Figure 5: Examples of laser-induced damages. The top picture of Figure 5 shows an example of a laser-induced damage without visible precursor, whereas the damage in the lower picture was generated near a visible defect. Images labeled with "DF before" and "DF after" are dark field micrographs taken before and after the raster scans, respectively. Images labeled "DF after C" show the result of the image analysis in which the connected pixels with an intensity above a specific threshold are colorized. Finally, the images labeled "BF, after" are Nomarski micrographs taken after irradiation.

\subsection{Laser-induced contamination measurements}

Space optics are typically intended to be used in vacuum and should thus be resistant to laser-induced contamination (LIC), which may originate from the outgassing of volatile components, e.g. from glues, insulation materials or electronic boards. We have recently developed an ISO technical report [11] describing the test methodology for LIC measurements. 
We compared the susceptibility of standard IBS coatings to optics that were optimized for laser-induced damage (using ion etching with conditions similar to optics \#027) in a test setup as depicted in Figure 6.

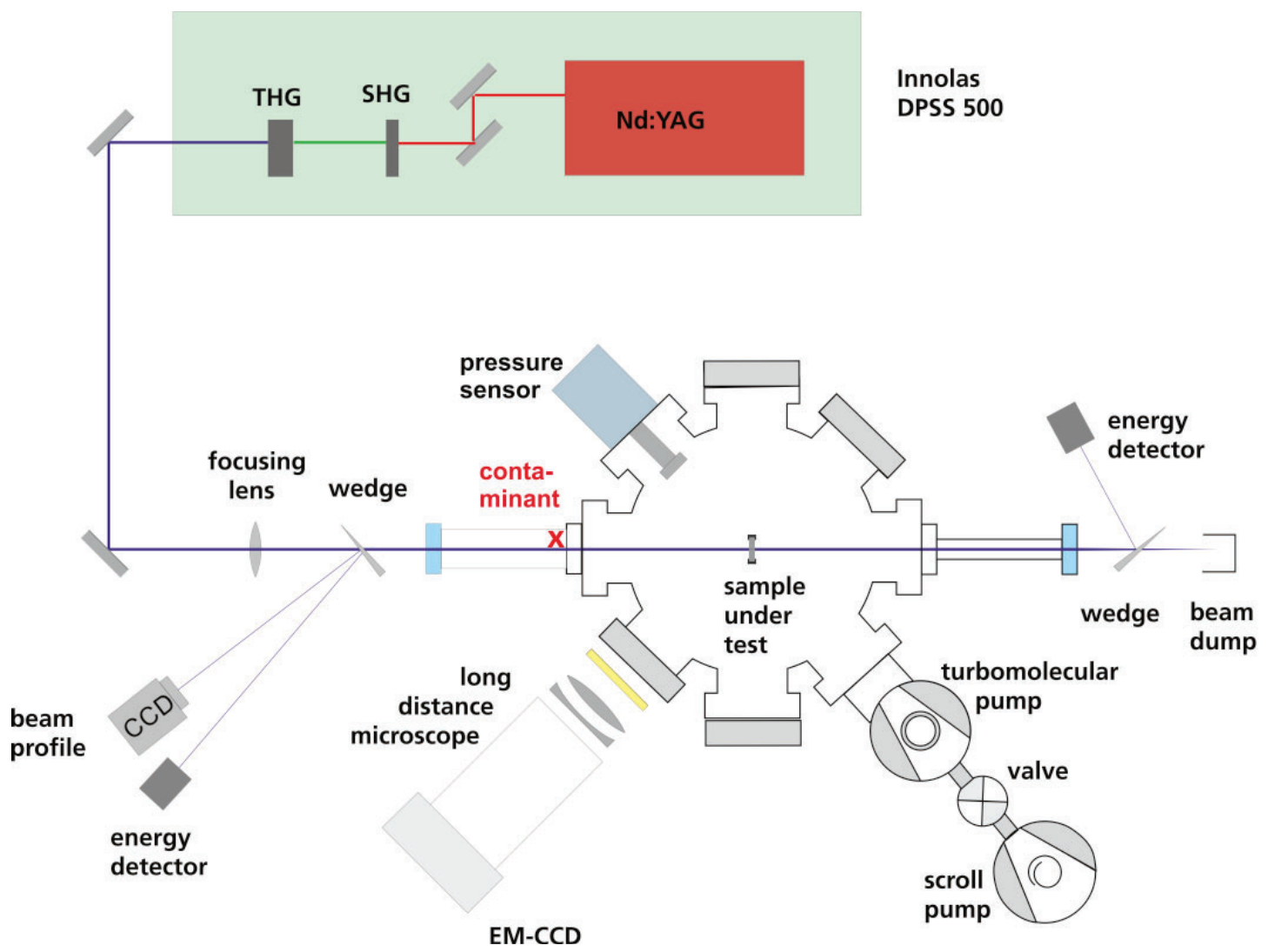

Figure 6: Schematic of the experimental setup for laser-induced contamination testing at $355 \mathrm{~nm}$.

In these tests, the sample is placed in a vacuum chamber $\left(<10^{-6}\right.$ mbar base pressure $)$ and is irradiated for $\sim 20$ hours with the $355 \mathrm{~nm}$, nanosecond-pulsed laser system also used for LIDT testing. As contaminant, the glue Armstrong A-12 (Loctite, Henkel Corporation, USA) on alumina foil was tested. The contaminant was heated to $100^{\circ} \mathrm{C}$ to enhance the outgassing and thus to speed up the deposit formation. The contamination growth was monitored in-situ by detecting the laser-induced fluorescence with a long-distance microscope and an electron multiplying CCD detector. Additional LIC tests have also been performed at the fourth harmonic of the Nd:YAG laser at $266 \mathrm{~nm}$. The 1/e beam diameter was $\sim 440 \mathrm{~nm}$ for LIC tests at $266 \mathrm{~nm}$ and $\sim 620 \mathrm{~nm}$ for LIC tests at $355 \mathrm{~nm}$.

\section{RESULTS}

\subsection{Successful optimization process of the optical coating manufacturing}

Figure 7 shows the number of damages (more precisely the number of "damages without detected precursor" as defined in section 2.3) for large-area raster scans with an energy density of $25 \mathrm{~J} / \mathrm{cm}^{2}$ (panel A) and $15 \mathrm{~J} / \mathrm{cm}^{2}$ (panel B). In the beginning we tested applying the particle mitigation techniques only to the substrate and not during the IBS sputtering process. Substrates of samples \#007 to \#013 were treated via ion etching and we varied the ion current (100 -300 mA), the ion energy (100-400 eV) and the incidence angle of the secondary ion source. Substrates of samples \#018 to \#022 were treated via laser etching and we varied the laser fluence and the scanning speed of the galvano scanner directing the etching laser beam to the sample. However, both methods showed no significant reduction of the damage density compared to the reference samples. 
In contrast to this, optics in which the particle mitigation techniques were not only applied to the substrate, but additionally also during the IBS coating, a strong reduction in the damage density was obtained for both the ion etching (samples \#023 to \#027) as well as for the laser etching (\#029 to \#034). For specific configurations (sample \#027 and \#034) optics could be obtained that showed no laser-induced damage with a diameter greater than $4.5 \mu \mathrm{m}$ when tested in a raster scan at $25 \mathrm{~J} / \mathrm{cm}^{2}$. It should be noted, that this improvement of the optical coatings is not only visible in the "damage density without visible precursor" as indicated in Figure 7, but also in the number of detected "defects and damages". For the interested reader, these results are provided in the appendix. Additionally, the improvement of the damage threshold has also been demonstrated in ramped raster scan tests as reported earlier. [9]

\section{A) Raster scans at $25 \mathrm{~J} / \mathrm{cm}^{2}$}

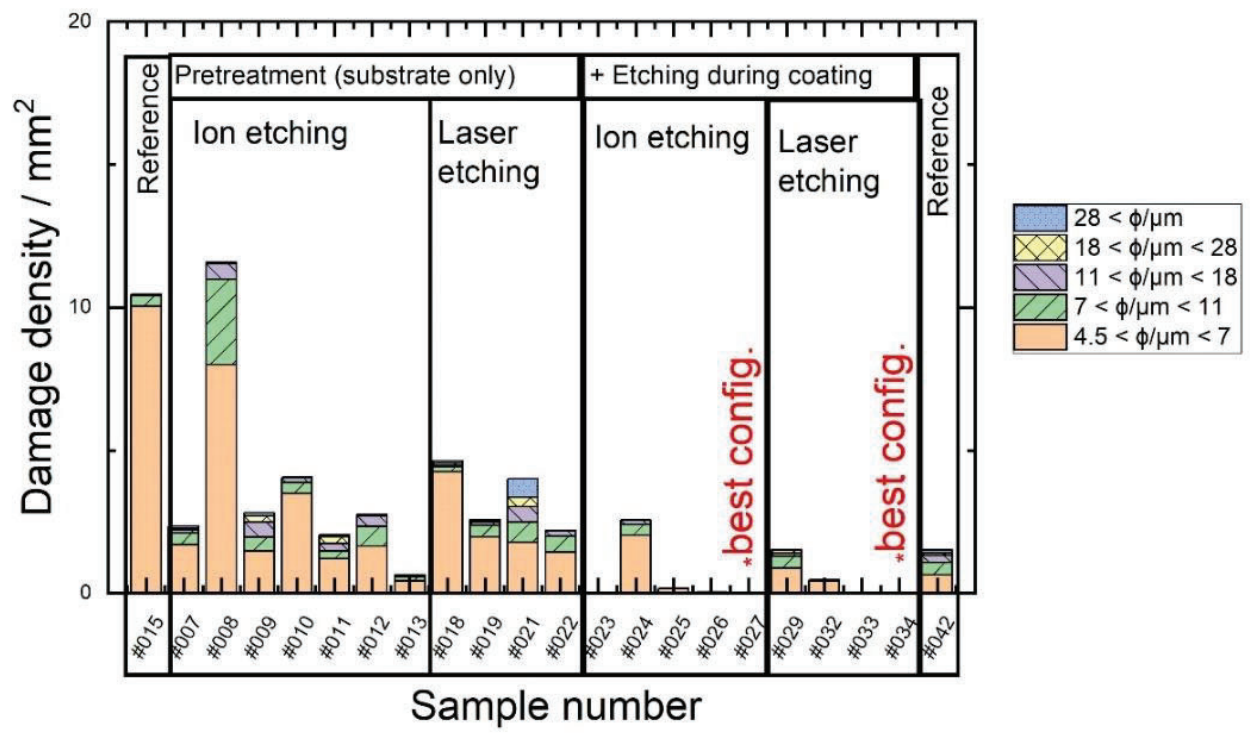

\section{B) Raster scans at $15 \mathrm{~J} / \mathrm{cm}^{2}$}

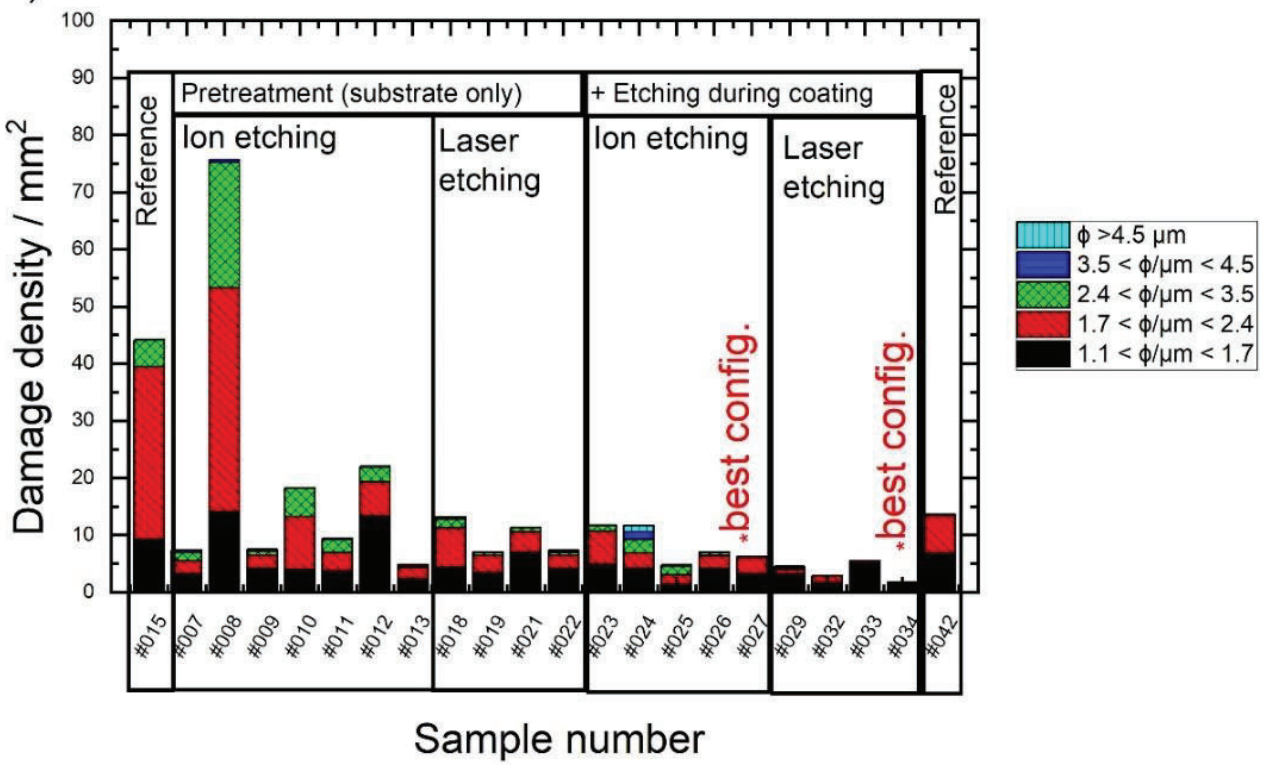

Figure 7: Improvement of the detected damage density during the optimization process of the particle mitigation scheme. 


\subsection{Laser-induced contamination testing of the optimized coating}

It has recently been shown, that nano-sized absorbers embedded in optical coatings can strongly enhance the formation of laser-induced deposits. [12] It has thus been a hope that laser optics manufactured using ion etching (with parameters similar to sample \#027) would be less susceptible to LIC than optics coated via conventional ion beam sputtering.

This was tested in LIC tests with the epoxy adhesive Armstrong A12 ( 600 mg per LIC test) at energy densities of 0.5 and $1 \mathrm{~J} / \mathrm{cm}^{2}$ and for the two wavelengths $355 \mathrm{~nm}$ and $266 \mathrm{~nm}$. The test duration was $\sim 20$ hours and the contaminant was heated to $100^{\circ} \mathrm{C}$ in the vicinity of the optics under test. Table 1 shows the height profiles of LIC deposits after tests with a laser fluence of $0.5 \mathrm{~J} / \mathrm{cm}^{2}$. Similar results for $1.0 \mathrm{~J} / \mathrm{cm} 2$ are given in Table 3 in the appendix.

Table 1: Height profiles of laser-induced deposits generated in LIC tests with Armstrong A12 with a laser fluence of $0.5 \mathrm{~J} / \mathrm{cm}^{2}$.

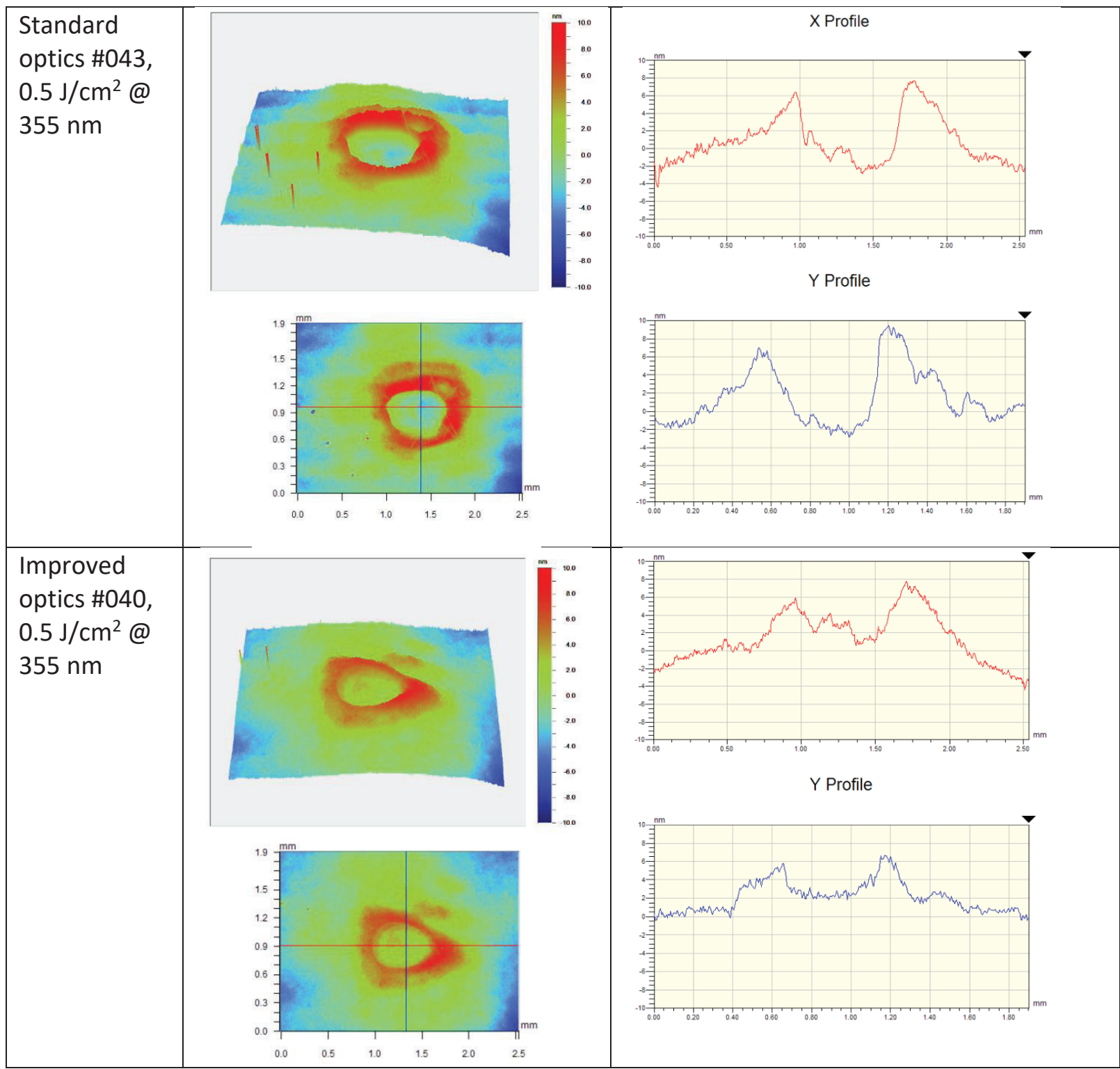




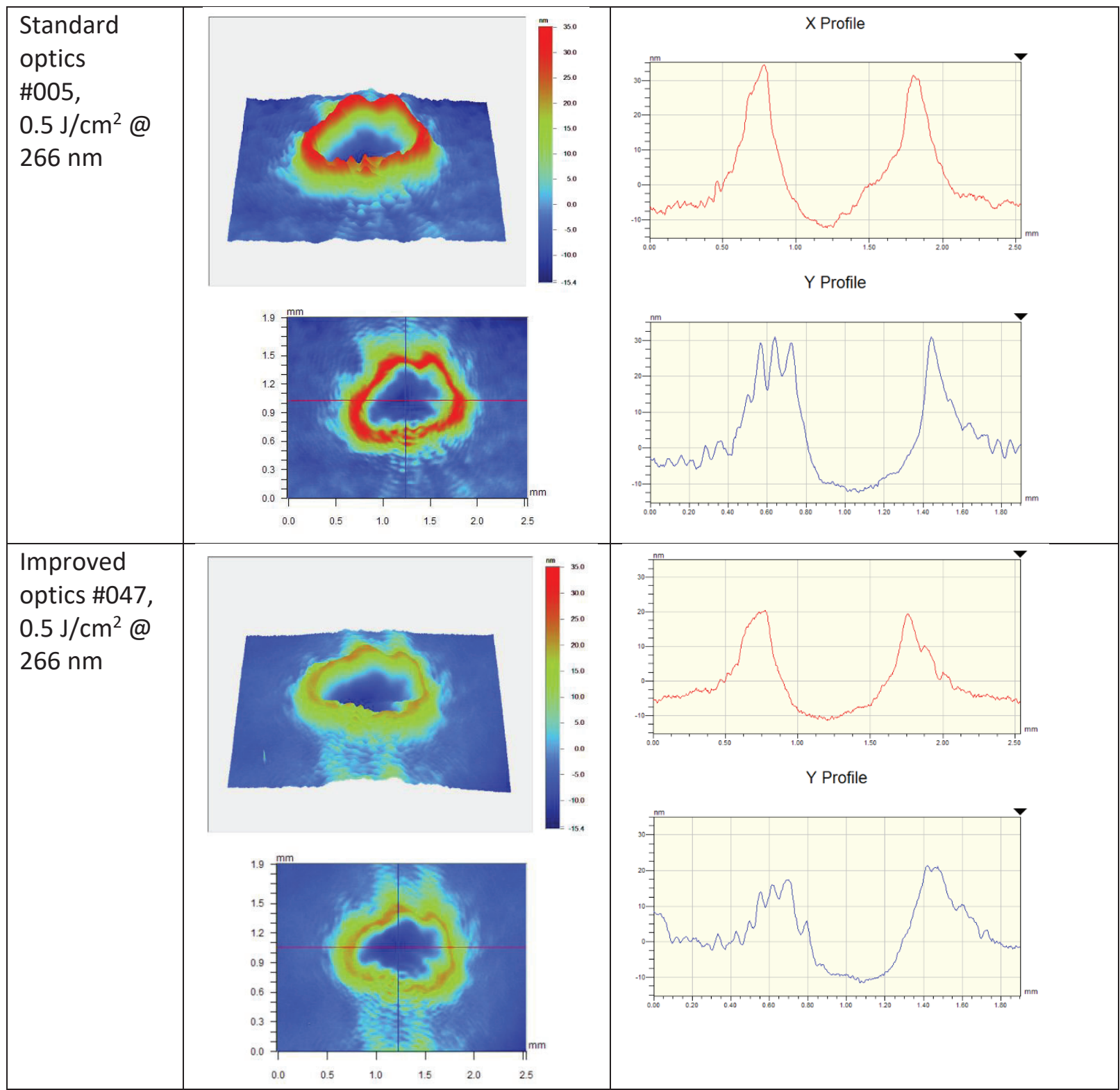

Several interesting findings can be deduced from Table 1:

1. All deposits show the typical "donut-shape" morphology [13, 14, 15]. The lateral dimension of these deposits extends beyond the 1/e $\mathrm{e}^{2}$ beam diameter of the LIC generating laser ( $\sim 620 \mathrm{~nm}$ for LIC tests at $355 \mathrm{~nm}$ and $440 \mathrm{~nm}$ at $266 \mathrm{~nm}$, respectively). This has recently been attributed to a thermally induced deposit growth driven via heat conduction from an absorbing (compacted) central part of the deposit. [16]

2. The deposits generated by the $266 \mathrm{~nm}$ laser have a much greater deposit height ( $\sim 30 \mathrm{~nm}$ to $40 \mathrm{~nm})$ compared to the deposits generated at $355 \mathrm{~nm}(\sim 10 \mathrm{~nm})$. This can probably be attributed to stronger ability of the 266nm laser (4.66 eV photon energy@ 266 nm versus $3.49 \mathrm{eV} @ 355 \mathrm{~nm}$ ) for breaking molecular bonds. A typical C-C chemical single bond has a binding energy of $3.6 \mathrm{eV}$ and a $\mathrm{C}-\mathrm{H}$ bond has a binding energy of $4.2 \mathrm{eV}$. This also means that it would be very challenging to build a nanosecond-pulsed LIDAR space laser operating at $266 \mathrm{~nm}$. 
3. Unfortunately, the laser optics that were optimized with respect to their LIDT via ion etching ("Improved optics") showed fairly similar deposit heights compared to the optics manufactured via conventional ion beam sputtering ("Standard optics"). It should however be noted, that UV anti-reflective IBS coatings (as tested in this work) are generally much less susceptible to LIC when compared to porous coatings (e.g. e-beam coatings). [18] For example, we have recently tested an e-beam coating with Armstrong A12 $\left(355 \mathrm{~nm}, 100 \mathrm{~Hz}, 0.4 \mathrm{~J} / \mathrm{cm} 2,100^{\circ} \mathrm{C}\right.$ contaminant temperature) and obtained a deposit height of $\sim 160 \mathrm{~nm}$ after only 1 hour of irradiation.

In principle, the formation of any laser-induced deposit should be considered as a laser-induced surface damage, defined in the ISO-21254 standard as "any permanent laser radiation-induced change of the surface characteristics of the specimen...". Indeed, the deposits as shown in Table 1 will induce a significant transmission loss (a few percent) of the AR coating and modify properties of the transmitted laser beam (e.g. the beam profile and the wavefront).

The continued irradiation of a laser-induced deposit can however also lead to the formation of a plasma and thus to an additional modification of surface or bulk material. $[17,18]$ In fact, this was observed in one LIC test on an improved laser optics at $355 \mathrm{~nm}$ resulting in a contamination-induced damage at a laser fluence of $1 \mathrm{~J} / \mathrm{cm}^{2}$ (all other optics remained undamaged during LIC testing). From in-situ fluorescence microscopy it can be concluded that this damage was formed in the center of the deposit after $\sim 10$ hours of irradiation (see Figure 8 ).

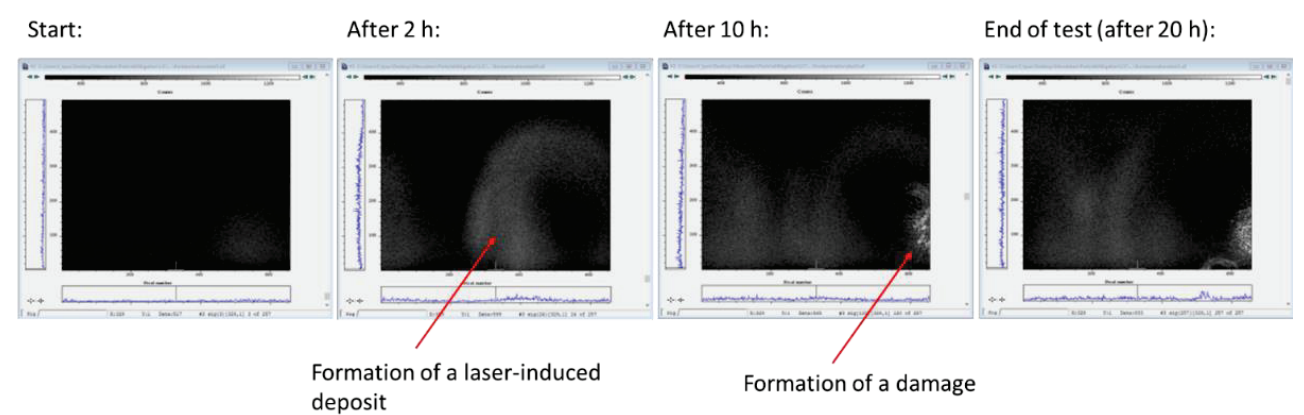

Figure 8: Formation of a laser-induced contamination and subsequently a contamination-induced damage monitored via insitu fluorescence microscopy.

A) Nomarski micrograph

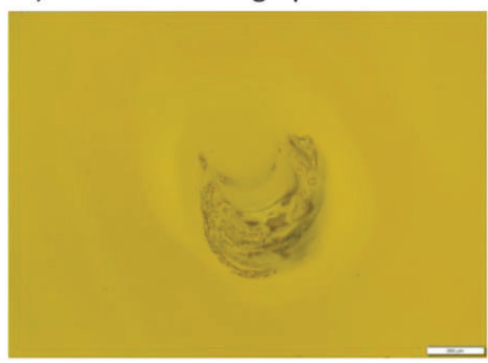

C) Raster electron micrograph

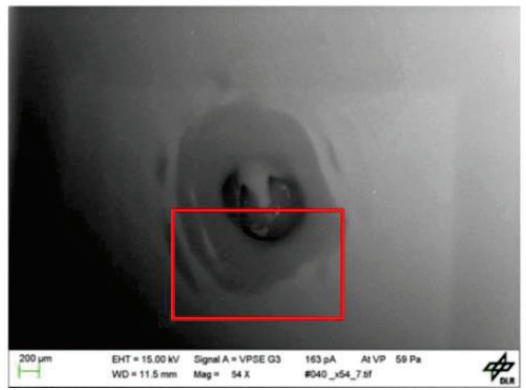

A) White-light interference micrograph

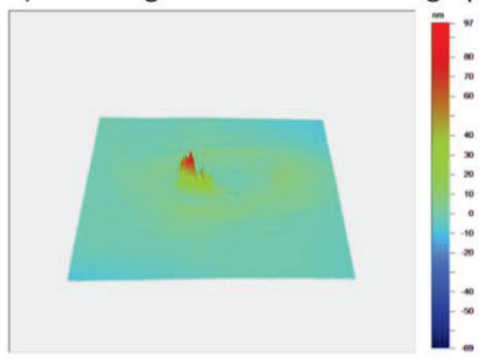

D) Raster electron micrograph (zoomed in)

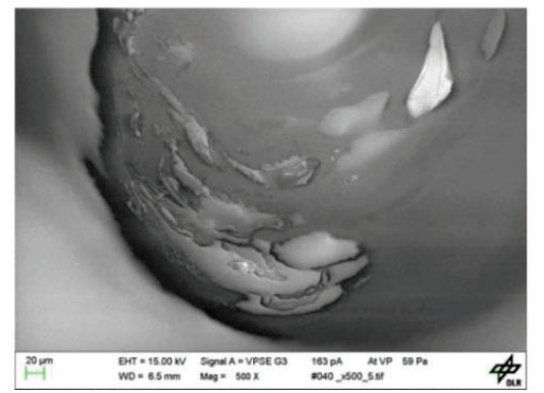

Figure 9: Microscopic images of the contamination/laser-induced damage. 
A subsequent inspection of the optical sample with Nomarski and raster electron microscopy showed that material was melted and distributed over the irradiated area (see Figure 9). This morphology can only be explained by the formation of a laser-induced plasma that locally heated the material above the melting point.

\section{DISUSSION \& OUTLOOK}

Large area raster scans allowed for a successful optimization of the manufacturing of IBS coated laser optics and particle mitigation schemes. For an efficient data evaluation, a Python script was programmed that counts and classifies damages in dark field microscopic images. The improved laser optics have the potential to increase the performance of future space lasers.

Optical coatings manufactured with the particle mitigation techniques showed no improvement with respect to their susceptibility for LIC when compared to standard IBS coatings. This means that LIC has to be well controlled (e.g. via the selection/avoidance of outgassing materials) to benefit from the improvement in damage resistance, in particular in case the optics shall be used in vacuum environment.

\section{FUNDING \& ACKNOWLEDGMENTS}

This work has been carried out under the ESA contract AO 1-8683/16/NL/BJ "Particle mitigation in high power laser optics". The authors would like to thank Ana Baselga Mateo (ESA-ESTEC) and Clemens Heese (ESA-ESTEC) for support and scientific advice during the initiation and execution of this project.

\section{REFERENCES}

[1] W. Riede, P. Allenspacher, M. Lammers, D. Wernham, A. Ciapponi, C. Heese, L. Jensen, H. Maedebach, S. Schrameyer und D. Ristau, "From ground to space: how to increase the confidence level in your flight optics", Laser-Induced Damage in Optical Materials: 2013, 2013.

[2] L. Gallais, J. Capoulade, J.-Y. Natoli und M. Commandré, "Investigation of nanodefect properties in optical coatings by coupling measured and simulated laser damage statistics", Journal of Applied Physics, 104, p. $053120,2008$.

[3] L. Jensen, S. Schrameyer, M. Jupé, H. Blaschke und D. Ristau, "Spot-size dependence of the LIDT from the NIR to the UV", Proceedings of SPIE - The International Society for Optical Engineering, 10, 2009.

[4] L. G. DeShazer, B. E. Newnam und K. M. Leung, "Role of coating defects in laser-induced damage to dielectric thin films", Applied Physics Letters, 23, pp. 607-609, 1973.

[5] T. W. Walker, A. Vaidyanathan, A. H. Guenther und P. Nielsen, "Impurity breakdown model in thin films", Laser induced damage in optical materials, 1979: proceedings of a symposium, 1980.

[6] ISO 21254-2:2011, "Lasers and laser-related equipment — Test methods for laser-induced damage threshold — Part 2: Threshold determination", 2011.

[7] L. Lamaignère, S. Bouillet, R. Courchinoux, T. Donval, M. Josse, J.-C. Poncetta und H. Bercegol, "An accurate, repeatable, and well characterized measurement of laser damage density of optical materials", Review of Scientific Instruments, 78, p. 103105, 2007.

[8] S. Schwartz, M. D. Feit, M. R. Kozlowski und R. P. Mouser, "Current 3-omega large optic test procedures and data analysis for the quality assurance of National Ignition Facility optics", Laser-Induced Damage in Optical Materials: 1998, 1999.

[9] T. Alig et al., "Prevention of laser damage precursors in spaceborne ultraviolet antireflection coatings", Optics Express, 2021 (submitted). 
[10] N. Bartels, P. Allenspacher und W. Riede, "Laser conditioning of UV anti-reflective optical coatings for applications in aerospace", Laser-Induced Damage in Optical Materials 2018: 50th Anniversary Conference, 2018.

[11] ISO/TR 20811:2017, "Optics and photonics — Lasers and laser-related equipment — Laser-induced molecular contamination testing", 2017.

[12] I. Balasa, M. Hippler, H. Schröder, L. Jensen, M. Gauch, D. Ristau und W. Riede, "Enhancement of contamination growth and damage by absorption centers under UV irradiation", p. 9237, 2014.

[13] M. Hippler, P. Wagner, H. Schroeder und W. Riede, "Laser-induced contamination of space borne laser systems: impact of organic contamination and mitigation by oxygen", Systems Contamination: Prediction, Control, and Performance 2016, 2016.

[14] H. Schröder, S. Borgmann, W. Riede und D. Wernham, "Investigation of laser induced deposit formation under space conditions", International Conference on Space Optics-ICSO 2008.

[15] G. G. El Reaidy, F. R. Wagner, D. Faye und J.-Y. Natoli, "Study of the first stages of laser-induced contamination", Optical Engineering, 57, p. 121903, 2018.

[16] F. R. Wagner, G. G. E. Reaidy, D. Faye und J.-Y. Natoli, "Laser induced deposits in contaminated vacuum environment: Optical properties and lateral growth", Optics \& Laser Technology, 122, p. 105889, 2020.

[17] P. Wagner, H. Schröder und W. Riede, "In-situ laser-induced contamination monitoring using long-distance microscopy", 9237, 2014, pp. 9237 - 9237 - 10.

[18] H. Schröder, P. Wagner, D. Kokkinos, W. Riede und A. Tighe, „Laser-induced contamination and its impact on laser damage threshold," Laser-Induced Damage in Optical Materials: 2014, 2014. 


\section{APPENDIX}

A) Before raster scan
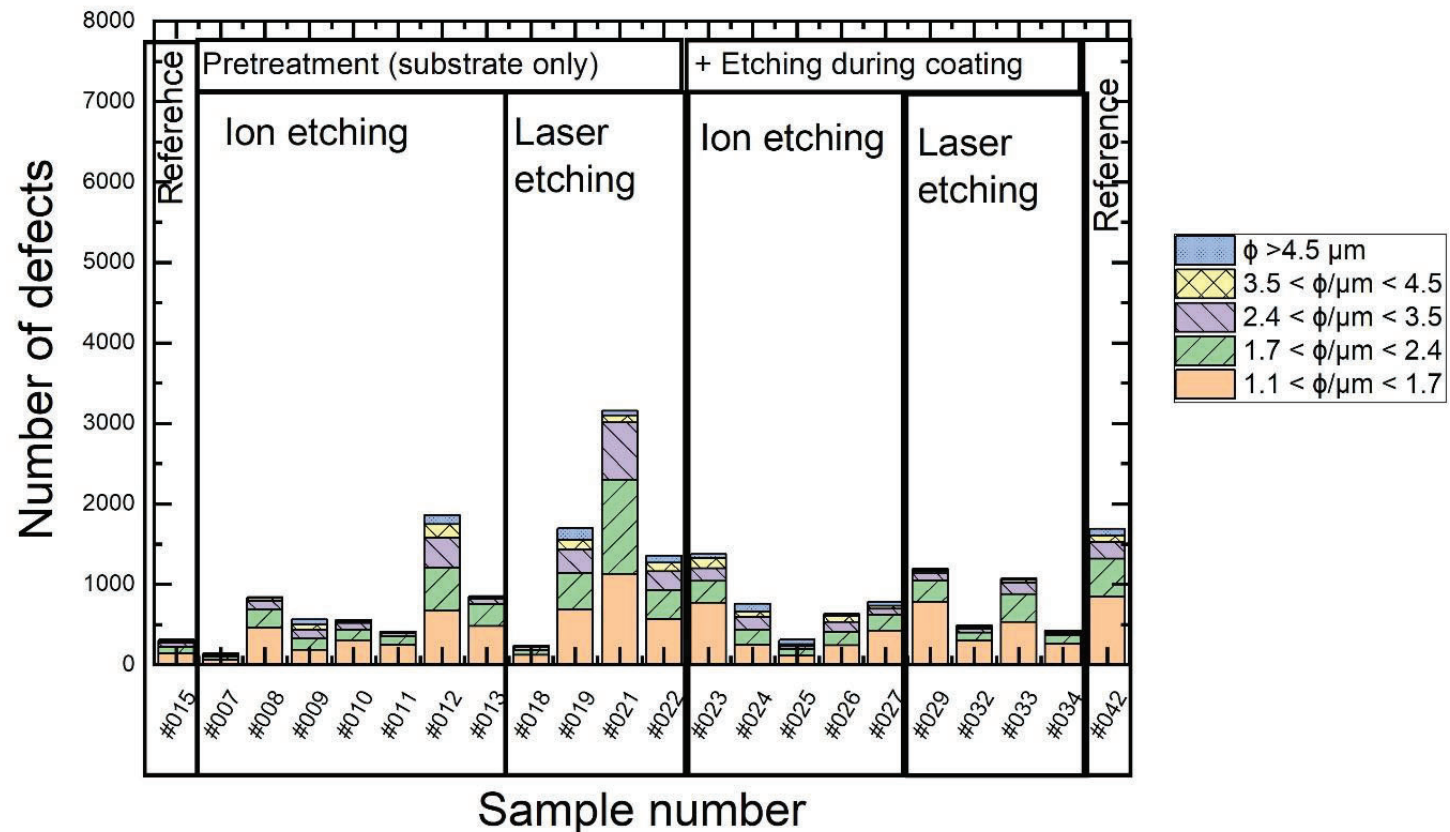

B) After raster scan at $15 \mathrm{~J} / \mathrm{cm}^{2}$

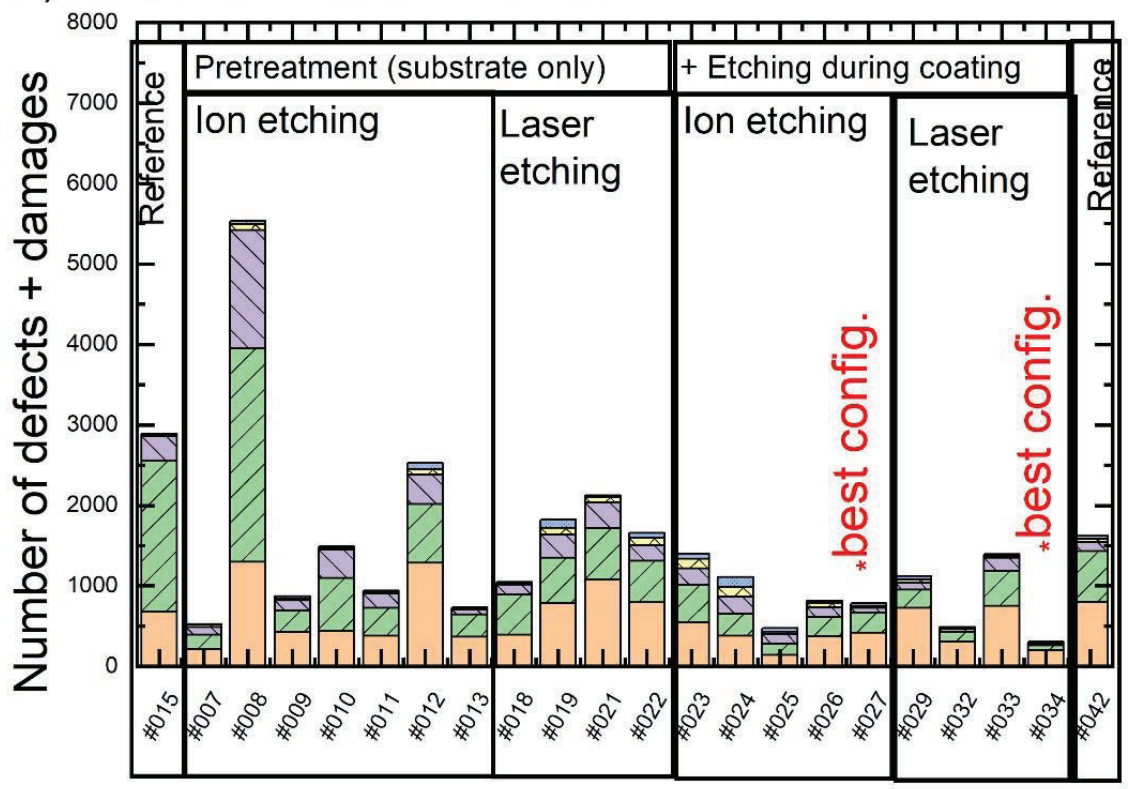

$\phi>4.5 \mu \mathrm{m}$

Х $3.5<\phi / \mu \mathrm{m}<4.5$

$2.4<\phi / \mu \mathrm{m}<3.5$

$\nabla 1.7<\phi / \mu \mathrm{m}<2.4$

$1.1<\phi / \mu \mathrm{m}<1.7$

\section{Sample number}

Figure 10: Detected number of objects before the raster scan (number of defects, panel A) and after the raster scan (number of defects and damages, panel B) at an energy density of $15 \mathrm{~J} / \mathrm{cm}^{2}$. 


\section{A) Before raster scan}

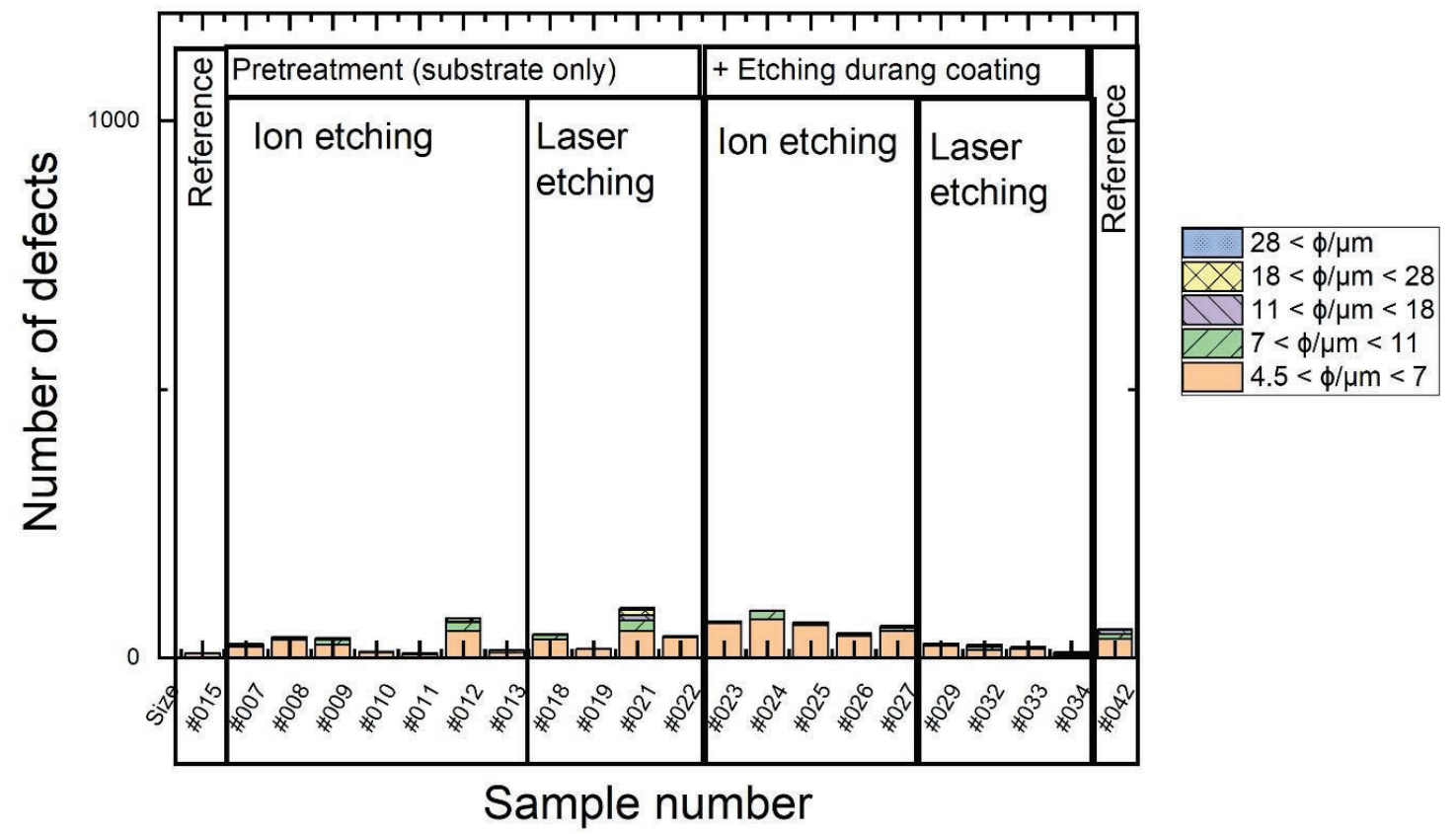

B) After raster scan at $25 \mathrm{~J} / \mathrm{cm}^{2}$
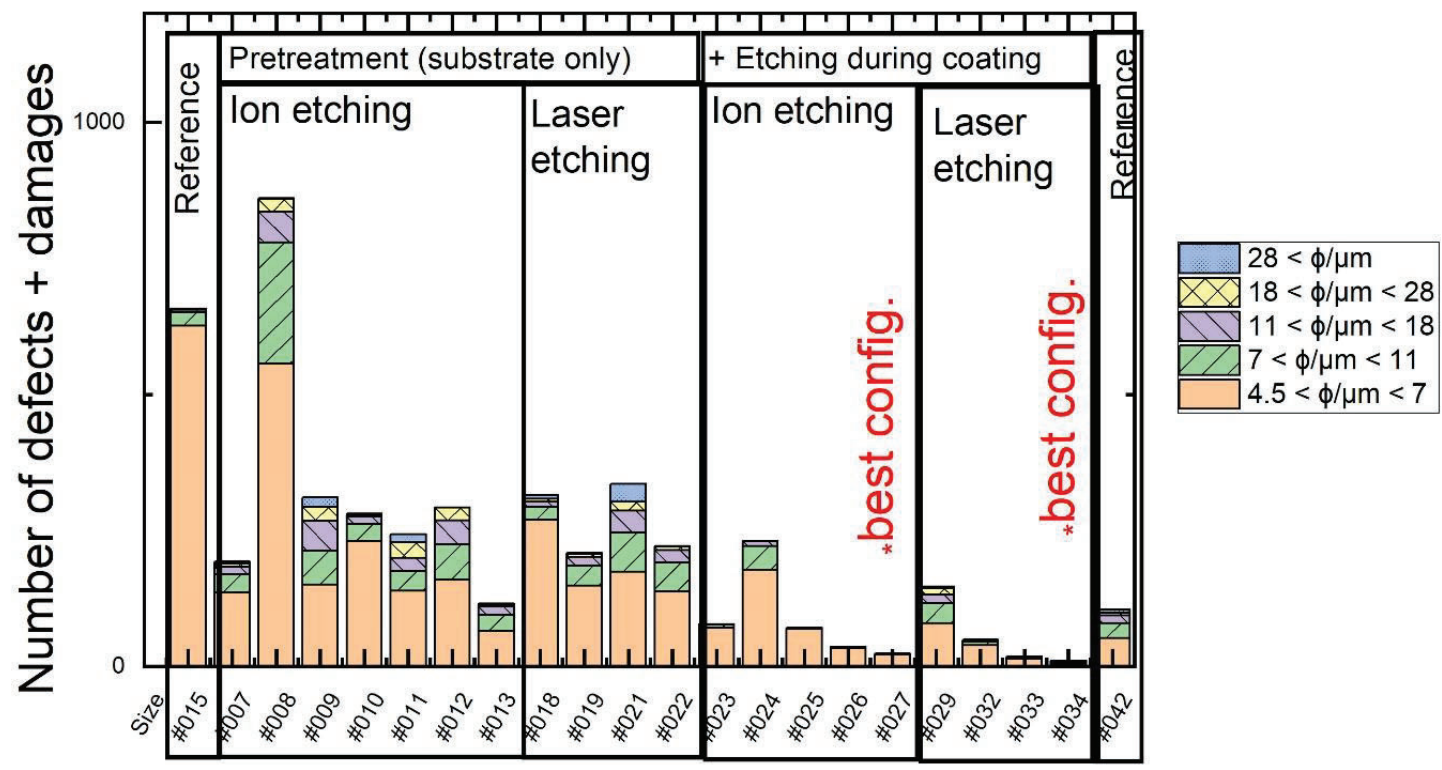

\section{Sample number}

Figure 11: Detected number of objects before the raster scan (number of defects, panel A) and after the raster scan (number of defects and damages, panel B) at an energy density of $25 \mathrm{~J} / \mathrm{cm}^{2}$. 
Table 2: Height profiles of laser-induced deposits generated in LIC tests with Armstrong A12 with a laser fluence of $1.0 \mathrm{~J} / \mathrm{cm}^{2}$.

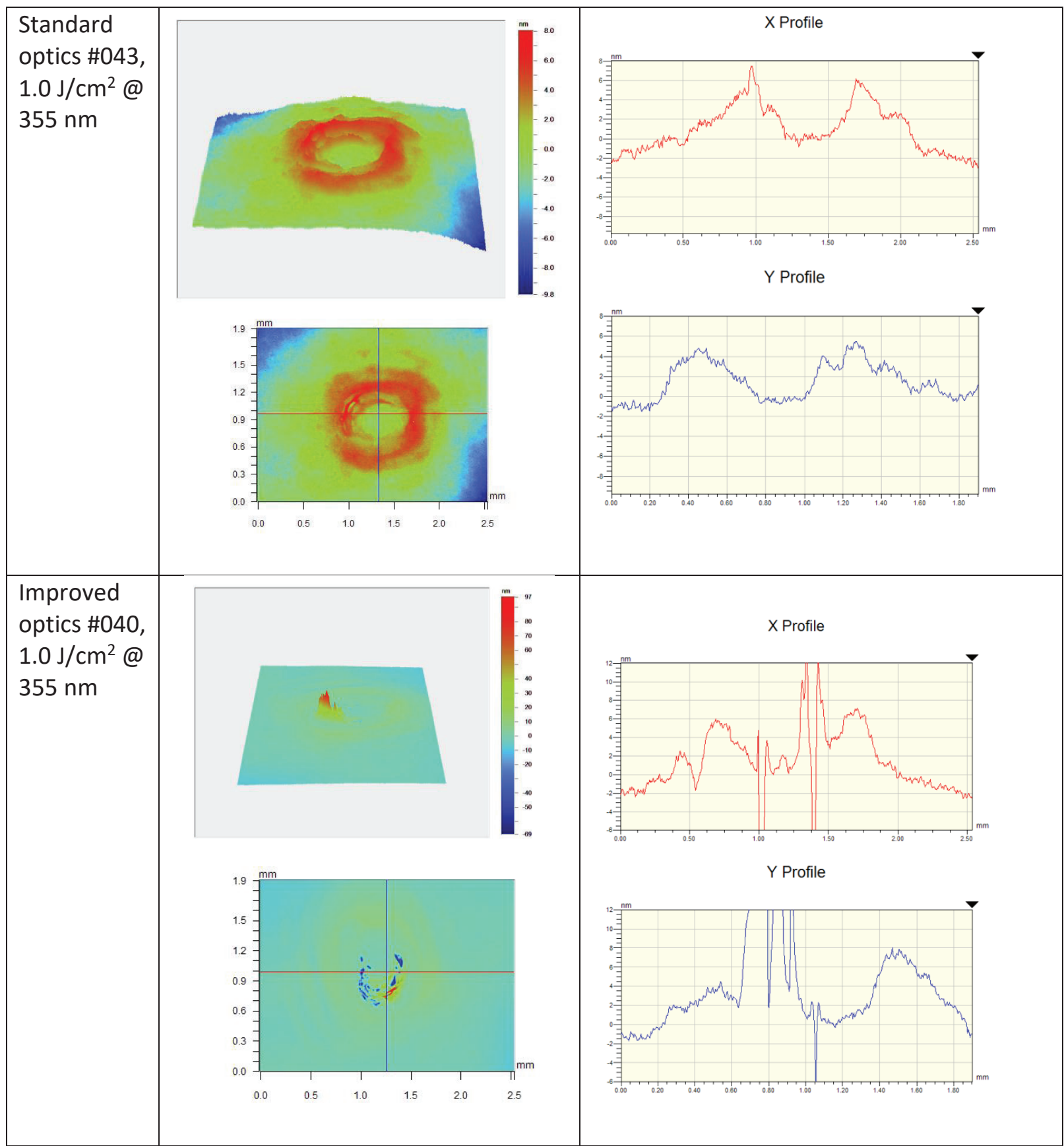




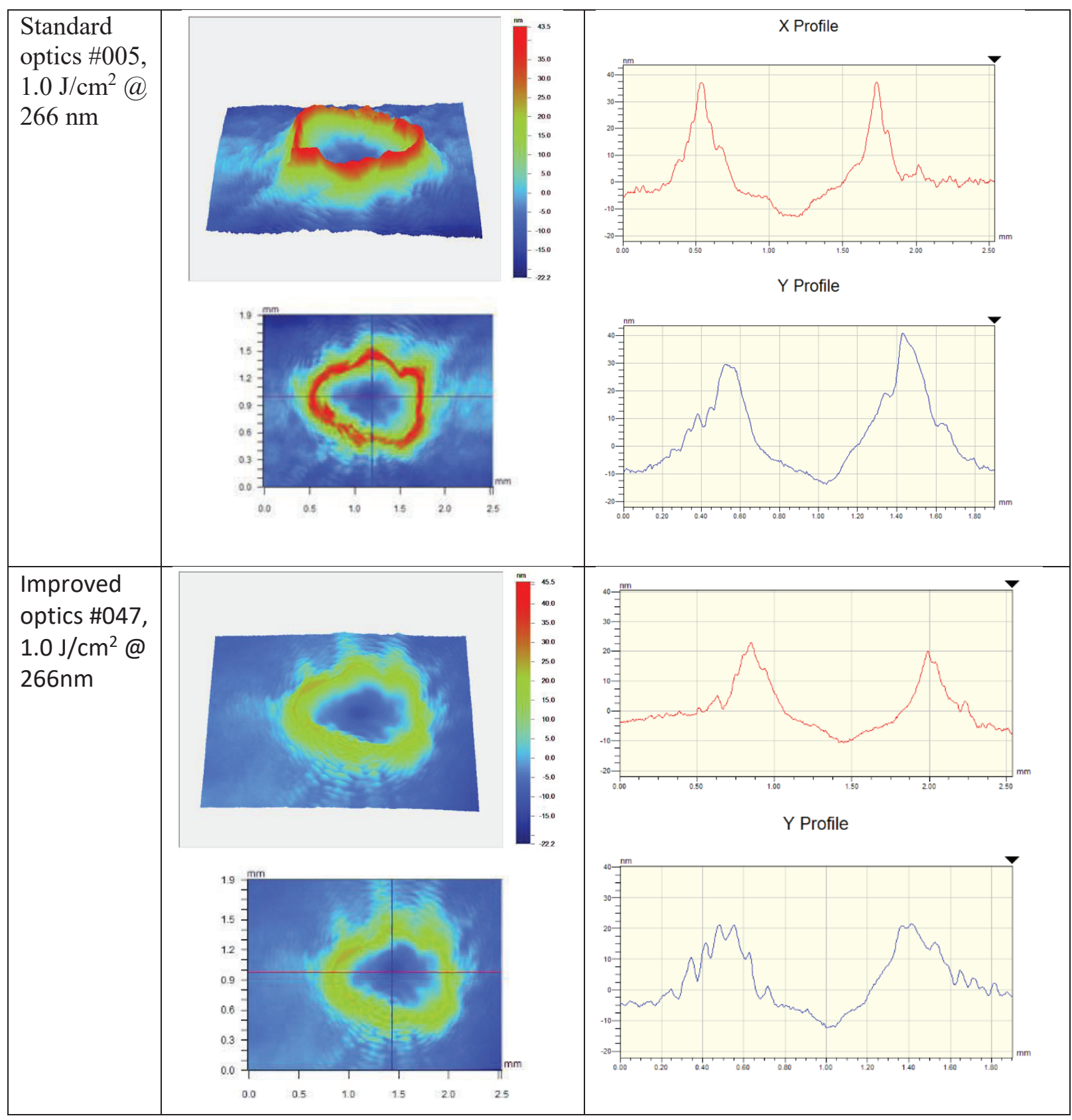

